\title{
PENGEMBANGAN BAHAN AJAR DIGITAL MOBILITAS PENDUDUK DAN KETENAGAKERJAAN BERBASIS STEM
}

\author{
Edwin Budi Prastyo ${ }^{1}$, Muhammad Naufal Islam², dan Alfyananda \\ Kurnia Putra ${ }^{3}$ \\ 1,2,3Universitas Negeri Malang \\ edwinprastyo99@gmail.com, mnaufalislam.1707216@students.um.ac.id, \\ Alfyananda.fis@um.ac.id
}

\begin{abstract}
ABSTRAK
Pembelajaran abad 21 mengarahkan guru untuk mengintegrasikan penggunakan teknologi dalam pembelajaran. Pembelajaran sebagai kegiatan dimana terjadi proses belajar seseorang secara sadar untuk memperoleh ilmu pengetahuan, keterampilan maupun tujuan pembelajaran yang melibatkan kedua pihak yaitu guru dan siswa, salah satunya dapat difasilitasi dengan menggunakan bahan ajar digital. Bahan ajar digital memberikan kemudahan dan kelancaran dalam proses pembelajaran melalui belajar aktif dan mandiri. Selain itu, manfaat bahan ajar dapat membantu memberikan informasi terkait materi, meningkatkan siswa untuk berpikir atau memahami, serta memberikan pengalaman langsung (konkret) agar berkembang secara berkelanjutan. Penelitian ini bertujuan untuk menghasilkan bahan ajar yang efisen dan efektif dalam menunjang proses pembelajaran Geografi secara optimal. Penelitian ini termasuk ke dalam penelitian dan pengembangan. Model penelitian dan pengembangan ini menggunakan model ADDIE. Berdasarkan prosedur pengembangan dilakukan uji validitas produk, baik pada validator ahli materi dan desain pada bahan ajar dinyatakan valid. Kemudian, berdasarkan hasil uji coba lapangan baik respon guru dan siswa mengenai bahan ajar digital memberikan respon cukup baik dengan klasifikasi bahan ajar sangat layak. Kesimpulan dari penelitian ini bahwa bahan ajar digital ini sebagai inovasi dalam pembelajaran untuk mendukung kompetensi dan kapabilitas siswa dalam penguasaan materi dengan bantuan teknologi.
\end{abstract}

Kata kunci: Pengembangan Bahan Ajar; STEM, Mobilitas Penduduk; Ketenagakerjaan, Pembelajaran Geografi 


\begin{abstract}
21st-century learning directs teachers to integrate the use of technology in learning. They are learning as an activity where a person's learning process occurs consciously to gain knowledge, skills, and learning objectives that involve both parties, namely teachers and students, which can be facilitated by using digital teaching materials. Digital teaching materials provide convenience and fluency in the learning process through active and independent learning. In addition, the benefits of teaching materials can help provide information related to the material, improve students' thinking or understanding, and provide direct (concrete) experience so that they develop sustainably. This study aims to produce efficient and effective teaching materials in supporting the Geography learning process optimally. This research is included in research and development. This research and development model uses the ADDIE model. Based on the development procedure, the product validity test was carried out, both on the material expert validator and the design on the teaching material was declared valid. Then, based on the results of field trials, both teacher and student responses regarding digital teaching materials gave a reasonably good response with the classification of teaching materials very feasible. This study concludes that digital teaching materials are an innovation in learning to support students' competencies and capabilities in mastering the material with the help of technology.
\end{abstract}

Keywords: Development of Teaching Materia; STEM; Population Mobility; Employment; Learning Geography.

\title{
PENDAHULUAN
}

Tuntutan dan tantangan pendidikan abad 21, mengubah paradigma pembelajaran dari konvensional menuju pembelajaran berbasis teknologi. Perubahan paradigma ini selaras dengan perkembangan teknologi yang semakin pesat di sector pendidikan. Orientasi pembelajaran abad 21 pembelajaran harus praktis dengan konektivitas tinggi keberbagai sumber belajar ${ }^{1}$. Siswa dalam rentang usia 16-19 tahun lebih banyak mengakses media elektronik, berita dan sosial media lebih dari 6 jam sehari ${ }^{2}$. Kondisi ini dapat dimanfaatkan sebagai peluang positif dalam implementasi inovasi pembelajaran berbasis teknologi.

1 Putra Dewi, Pratisia, "Implementasi Pemanfaatan Google Classroom , Google Meet , Dan Instagram Dalam Proses Pembelajaran Online Menuju Abad 21," Jurnal Integrasi Dan Harmoni Inovatif Ilmu-Ilmu Sosial 1, no. 5 (2021): 533-41, https://doi.org/10.17977/ um063v1i52021p533-541; Fitri Dia et al., "Improving Critical Thinking Ability : Earthcomm Learning For Watershed Conservation Materials" 3, no. 2 (2021): 99-106; Caroline Haythornthwaite, "Learning, Connectivity and Networks," Information and Learning Science, 2019, https://doi.org/10.1108/ILS-06-2018-0052.

2 Kristin Blagg et al., "Mapping Student Needs during COVID-19 An Assessment of Remote Learning Environments," EDUCATION DATA AND POLICY CENTER, 2020. 
Pembelajaran abad 21 menuntut guru untuk mengintegrasikan penggunakan teknologi dalam pembelajaran. Pembelajaran sebagai aktivitas yang dilakukan secara sadar untuk memperoleh informasi berupa pengetahuan dan keterampilan ${ }^{3}$. Kegiatan pembelajaran idealnya terdiri atas komponen pembelajaran yang dikonstruksi melalui teknologi digital ${ }^{4}$. Teknologi digital diintegrasikan dalam strategi pembelajaran sehingga terjadi penyampaian informasi secara optimal ${ }^{5}$. Salah satu komponen pembelajaran yang relevan untuk digunakan pada pembelajaran abad 21 berupa bahan ajar digital.

Bahan ajar digital merupakan komponen penting dalam tercapainya tujuan pembelajaran. Aksesibilitas konten pada bahan ajar digital dapat menunjang proses pembelajaran secara efektif dan efisen ${ }^{6}$. Pada aspek kognisi, bahan ajar digital dapat mempermudah siswa dalam memahami konsep materi serta meningkatkan daya nalar ${ }^{7}$. Kemudian, bahan ajar digital membantu siswa dalam melakukan pendalaman materi dengan aktivitas belajar siswa berupa berpikir dan memahami, serta memberikan pengalaman nyata (konkret) agar tercipta pembelajaran berkelanjutan ${ }^{8}$. Keberhasilan implementasi bahan ajar digital dalam menunjang proses pembelajaran bergantung pada guru sebagai fasilitator dalam kegiatan pembelajaran.

Penelitian ini dilaksanakan di SMAN 1 Kediri, dengan pertimbangan bahwa Kota Kediri menjadi pusat karesidenan Kediri dengan tingkat mobilitas tenaga kerja yang tinggi jika dibandingkan dengan kota lain di karesidenan Kediri.

3 Lin Lin et al., "From Knowledge and Skills to Digital Works: An Application of Design Thinking in the Information Technology Course," Thinking Skills and Creativity 36 (2020), https://doi.org/10.1016/j.tsc.2020.100646.

4 Lalu Sumardi, Arif Rohman, and Dwi Wahyudiati, "Does the Teaching and Learning Process in Primary Schools Correspond to the Characteristics of the 21st Century Learning?," International Journal of Instruction 13, no. 3 (2020), https://doi.org/10.29333/iji.2020.13325a; Eloho Ifinedo and Marja Kankaanranta, "Understanding the Influence of Context in Technology Integration from Teacher Educators' Perspective," Technology, Pedagogy and Education, 2021, https://oi.org/10.1080/1475939X.2020.1867231.

5 Mohd Fadzil Abdul Hanid, Mohd Nihra Haruzuan Mohamad Said, and Noraffandy Yahaya, "Learning Strategies Using Augmented Reality Technology in Education: MetaAnalysis," Universal Journal of Educational Research 8, no. 5 A (2020), https://doi. org/10.13189/ujer.2020.081908.

6 Tim Surma and Paul A. Kirschner, "Virtual Special Issue Computers in Human Behavior Technology Enhanced Distance Learning Should Not Forget How Learning Happens," Computers in Human Behavior, 2020, https://doi.org/10.1016/j.chb.2020.106390.

7 Natalia Lara Nieto-Márquez, Alejandro Baldominos, and Miguel Ángel PérezNieto, "Digital Teaching Materials and Their Relationship with the Metacognitive Skills of Students in Primary Education," Education Sciences 10, no. 4 (2020), https://doi.org/10.3390/ educsci10040113.

8 V. Cook et al., "Developing Material-Dialogic Space in Geography Learning and Teaching: Combining a Dialogic Pedagogy with the Use of a Microblogging Tool," Thinking Skills and Creativity 31 (2019), https://doi.org/10.1016/j.tsc.2018.12.005. 


\section{Edwin Budi Prastyo dkk, Pengembangan Bahan Ajar Digital}

Pemilihan lokasi juga mempermudah pengembangan bahan ajar digital dengan pendekatan kontekstual. Hasil analisis kebutuhan mengenai bahan ajar digital di SMAN 1 Kediri menunjukkan dalam proses pembelajaran guru Geografi memiliki kecenderungan untuk menggunakan bahan ajar versi cetak (hardfile). Kondisi demikian berbanding terbalik dengan kebutuhan siswa yang lebih tertarik menggunakan bahan ajar versi digital dengan penyajian materi berupa gambar, infografis, dan video berbasis multimedia. Selain itu, pendalaman konten pada proses pembelajaran dilakukan pada level kognitif tingkat rendah. Sedangkan, tuntutan pembelajaran abad 21 dengan menggunakan bahan ajar berbasis digital melalui pencapaian berpikir tingkat tinggi ${ }^{9}$ yang akan menarik minat siswa serta sesuai dengan karakteristik gaya belajar generasi digital saat ini. Mengingat generasi saat ini erat kaitannya dengan integrasi teknologi digital ${ }^{10}$.

Pengembangan bahan ajar digital ini menggunakan pendekatan STEM (Sains, Technology, Engineering, and Mathematic). Pendekatan STEM dalam pembelajaran membantu menghadrikan proses pembelajaran integratifkomprehensif ${ }^{11}$. Kondisi demikian dapat menciptakan aktivitas pembelajaran yang inovatif dan kreatif ${ }^{12}$, serta kompetensi dan keterampilan siswa yang sesuai dengan tuntutan dimasa depan ${ }^{13}$.

\section{METODE PENELITIAN}

Desain penelitian ini merupakan penelitian dan pengembangan (R\&D). Prosedur penelitian dan pengembangan berorientasi pada pembaharuan terhadap suatu produk melalui validasi hingga uji coba untuk menjamin

9 H. Mubarok, N. Suprapto, and A. S. Adam, "Using Inquiry-Based Laboratory to Improve Students' Higher Order Thinking Skills (HOTs)," in Journal of Physics: Conference Series, vol. 1171, 2019, https://doi.org/10.1088/1742-6596/1171/1/012040.

10 Alfyananda Kurnia Putra et al., "Effect of Mobile-Augmented Reality (MAR) in Digital Encyclopedia on The Complex Problem Solving and Attitudes of Undergraduate Student," International Journal of Emerging Technologies in Learning (IJET) 16, no. 07 (2021), https:// doi.org/10.3991/ijet.v16i07.21223; Alfyananda Kurnia Putra, "The Effect of Blended ProjectBased Learning with Stem Approach to Spatial Thinking Ability and Geographic Skill” 14, no. 3 (2021): 685-704.

11 Sri Retnowati, "The STEM Approach: The Development of Rectangular Module to Improve Critical Thinking Skill.," International Online Journal of Education and Teaching 7, no. 1 (2020).

12 Thi Phuoc Lai Nguyen, Thi Huy Nguyen, and Thanh Khiet Tran, "STEM Education in Secondary Schools: Teachers' Perspective towards Sustainable Development," Sustainability (Switzerland) 12, no. 21 (2020), https://doi.org/10.3390/su12218865.

13 Lisa Steffensen, "Climate Change and Students' Critical Competencies: A Norwegian Study," 2020, https://doi.org/10.1007/978-3-030-52229-2_15. 
kualitas produk yang dihasilkan ${ }^{14}$. Pada model penelitian dan pengembangan ini menggunakan model ADDIE dengan prosedur tahapan 1) Analysis; 2) Design; 3) Develop; 4) Implementation; and 5) Evaluation ${ }^{15}$. Pemilihan model pengembangan $A D D I E$ berdasarkan pada struktur prosedur yang sistematis sehingga relevan dengan pengembangan buku ajar digital ${ }^{16}$.

Kemudian, pengembangan bahan ajar digital dilakukan uji coba produk (guru dan siswa) dan validator ahli (media dan materi). Subjek uji coba dari bahan ajar digital ini adalah siswa kelas XII Ilmu Sosial dengan jumlah 25 siswa di Sekolah Menengah Atas 1 Kediri dengan desain uji coba terbatas. Teknik pemilihan subjek uji coba dilakukan dengan teknik purposive sampling dengan kriteria siswa yang telah mempelajari sub materi mobilitas penduduk dan tenaga kerja. Instrumen pengumpulan data dalam penelitian pengembangan ini menggunakan instrumen berbentuk angket yang digunakan untuk memperoleh informasi uji coba dari validator ahli (media dan materi) dan pengguna (guru dan siswa).

\section{HASIL DAN PEMBAHASAN}

Hasil produk pengembangan bahan ajar digital sub materi Mobilitas Penduduk dan Ketenagakerjaan. Secara struktural, materi Mobilitas dan Ketenagakerjaan terdapat beberapa materi pokok yang terdiri 1) Definisi Mobilitas Penduduk; 2) Faktor-Faktor yang Mempengaruhi Mobilitas Penduduk; 3) Kendala Mobilitas Penduduk; 4) Jenis Mobilitas Penduduk; dan 5) Dampak Mobilitas Penduduk terhadap Ketenagakerjaan. Berdasarkan penjabaran pada materi Mobilitas Penduduk dan Ketenagakerjaan, pengembangan bahan ajar digital berdasarkan pada penyusunan bahan ajar inovatif. Struktur bahan ajar digital meliputi 1) Identitas Bahan Ajar; 2) Terkait Buku Ini; 3) Kompetensi Dasar (Materi Pokok); 4) Informasi Pendukung; dan 5) Evaluasi ${ }^{17}$, yang ditunjukkan pada tabel 1 berikut:

${ }^{14}$ Munir Tubagus, Suyitno Muslim, and Suriani, "Development of Learning Management System-Based Blended Learning Model Using Claroline in Higher Education,” International Journal of Interactive Mobile Technologies 14, no. 6 (2020), https://doi.org/10.3991/IJIM. V14I06.13399.

15 Abdullah M. Almelhi, "Effectiveness of the ADDIE Model within an E-Learning Environment in Developing Creative Writing in EFL Students," English Language Teaching 14, no. 2 (2021), https://doi.org/10.5539/elt.v14n2p20.

16 Alim Salamah, Rabiatul Adawiah Ahmad Rashid, and Mukhtar, "The Development Of Citizenship Education Learning Models Through The Addie Model To Improve Student Characters At Mulawarman University," Palarch's Journal of Archaeology of Egypt/ Egyptology 17, no. 9 (2020); Almelhi, "Effectiveness of the ADDIE Model within an E-Learning Environment in Developing Creative Writing in EFL Students."

17 Prastowo Andi, Panduan Kreatif Membuat Bahan Ajar Inovatif: Menciptakan Metode Pembelajaran Yang Menarik Dan Menyenangkan, Diva Press, 2011. 
154 Edwin Budi Prastyo dkk, Pengembangan Bahan Ajar Digital

Tabel 1. Struktur Materi Ajar Digital Mobilitas Penduduk dan Pekerjaan

\begin{tabular}{cll}
\hline No & $\begin{array}{c}\text { Struktur Materi } \\
\text { Bahan Ajar Digital }\end{array}$ & \\
\hline 1 & Identitas Bahan Ajar & $\begin{array}{l}\text { Identitas Bahan Ajar } \\
\text { a) Physical Form: Bahan Ajar Digital } \\
\text { b) Title: Mobilitas dan Pekerjaan Era Digital } \\
\text { c) Target: Siswa Kelas XI Mata Pelajaran Geografi }\end{array}$ \\
\hline 2 & User Guide & $\begin{array}{l}\text { Berisi aksesibilitas (fitur) yang digunakan dalam bahan ajar } \\
\text { digital serta pedoman penggunaan oleh pengguna. }\end{array}$ \\
\hline 3 & Basic competencies & $\begin{array}{l}\text { Materi pokok bahan ajar dan kompetensi/kapabilitas yang } \\
\text { harus dicapai oleh siswa. }\end{array}$ \\
\hline 4 & Supporting Information & $\begin{array}{l}\text { Berisi informasi pendukung yang mendukung pendalaman } \\
\text { materi. Informasi pendukung dalam bahan ajar berfungsi } \\
\text { untuk memperkaya pengetahuan dan pemahaman konsep } \\
\end{array}$ \\
& & siswa. \\
\hline 5 & Evaluation & Berisi soal evaluasi terkait materi yang disajikan dalam \\
& & bentuk kuis pilihan ganda. \\
\hline
\end{tabular}

Hasil uji coba bahan ajar digital terdiri dari 2 aspek utama yaitu (1) aspek materi dan (2) aspek desain. Aspek materi terdiri dari pertanyaan tanggapan siswa terkait kejelasan materi dalam bahan ajar digital tersebut. Persentase tertinggi pada aspek materi yaitu poin ke-1 dan ke-3 mengenai keterkinian (keterbaruan) materi dan ilustrasi, gambar, video yang dapat mendukung materi yang dikembangkan. Sedangkan persentase terendah pada aspek materi yaitu poin ke-9 mengenai terdapatnya unsur matematika dalam bahan ajar. Hal tersebut dikarenakan unsur bahan ajar seperti rumus perhitungan mobilitas disajikan dalam link video dari youtube yang mungkin beberapa siswa terlewat tidak membacanya.

Aspek desain sebagai aspek kedua dimana terdiri dari 9 poin yang disajikan dalam butir penilaian pada angka 13-21. Persentase tertinggi pada aspek desain yaitu poin ke-17 dengan persentase $98 \%$ mengenai layout bahan ajar tidak mengurangi unsur materi. Sedangkan persentase terendah pada aspek desain yaitu poin ke-21 dengan persentase $88 \%$ mengenai terdapatnya latihan soal yang sesuai dengan materi. Latihan soal sudah dipertimbangkan peneliti sehingga dapat dijadikan sebagai gambaran awal sejauh mana pemahaman siswa setelah menggunakan bahan ajar digital ${ }^{18}$.

Kemudian, hasil uji penelitian dan pengembangan menghasilkan data kuantitatif tanggapan siswa disajikan dalam angket terbuka. Siswa pengguna

18 Kusuma Dewi and Alfyananda Kurnia Putra, "Pengembangan Bahan Ajar Digital Berbasis STEM Dengan Pendekatan Eco-Spatial Behavior Materi Kependudukan Development of STEM-Based Digital Teaching Materials with an Eco- Spatial Behavior Approach for Population Materials," JPIPS : Jurnal Pendidikan Ilmu Pengetahuan Sosial 7, no. 2 (2021): 92-102, https://doi.org/10.15548/jpips.v7i2.11960. 
dapat memberikan masukan berupa kritik dan saran mengenai pengembangan bahan ajar digital. Akumulasi saran mengenai pengembangan bahan ajar digital sebagai berikut 1) Akses pada perangkat smartphone harus mengubah rotasi layar pada perangkat menjadi landscape; 2) Fitur matrix code pada smartphone harus terintegrasi fitur scan; 3) Rotasi potrait saat akses bahan ajar digital menjadikan tampilan bahan ajar terpotong; 4) Perlunya efek blocking pada kalimat dengan menggunakan warna berbeda. Selain itu, pada penelitian dan pengembangan bahan ajar digital untuk mengetahui pemahaman siswa dalam penggunaan bahan ajar digital.

Hasil tes pemahaman dilakukan secara online terhadap 25 siswa XII ilmu sosial sebagai partisipan. Tes pemahaman disajikan dalam bentuk quiz yang terintegrasi dalam bahan ajar digital. Quiz tersebut terdiri dari 10 soal pilihan ganda yang sebelumnya telah dilakukan breakdown indikator soal, yang ditunjukkan pada tabel 2 sebagai berikut.

\section{Tabel 2. Hasil Uji Coba Pemahaman Penggunaan Bahan Ajar Digital Mobilitas Kerja dan Ketenagakerjaan}

\begin{tabular}{ccccc}
\hline No & $\begin{array}{c}\text { Interval Skor } \\
(\%)\end{array}$ & Kriteria & Frekuensi siswa & Persentase \\
\hline 1 & $76-100$ & Sangat Tinggi & 17 & $77 \%$ \\
\hline 2 & $51-75$ & Tinggi & 2 & $9 \%$ \\
\hline 3 & $26-50$ & Rendah & 3 & $14 \%$ \\
\hline 4 & $0-25$ & Sangat Rendah & - & - \\
\hline
\end{tabular}

Pada tabel tersebut memperlihatkan hasil tes pada interval skor 76-100 mendapatkan persentase paling tinggi yaitu 77\%. Sedangkan, interval skor terendah antara rentang 51-75 yaitu 9\%. Dengan Kriteria Ketuntasan Minimal (KKM) pada mata pelajaran Geografi di SMA Negeri 1 Kediri yaitu 75, artinya terdapat 5 siswa yang nilainya tidak memenuhi KKM. Kondisi demikian menunjukkan bahwa bahan ajar digital efektif dalam menunjang proses pembelajaran Geografi, sehingga dapat diambil kesimpulan bahwa bahan ajar digital ini membantu memudahkan siswa dalam memahami materi Mobiitas Penduduk dan Ketenagakerjaan.

\section{PENUTUP}

Pengembangan bahan ajar digital page flip berbasis STEM berbantuan matrix code technology pada sub materi Mobilitas Penduduk dan Tenaga Kerja memiliki kedudukan penting dalam pembelajaran Geografi. Pengemasan konten pada bahan ajar dengan bersifat terintegrasi STEM membantu berpikir sistematis dan struktural siswa. Efisiensi dan efektifitas pendalaman konten 
berbantuan matrix code technology. Pengembangan bahan ajar digital page flip telah sesuai dengan prosedur dan kaidah ilmiah dengan berbantuan model ADDIE yang meliputi Analysis, Design, Development, Implementation, and Evaluation. Hasil validasi ahli materi dan media menunjukkan kualitas bahan ajar secara valid dan layak digunakan. Hal ini ditunjang dengan rekapitulasi dan tingkat pemahaman pada uji coba produk yang menunjukkan bahan ajar digital page flip berbasis STEM dengan matrix code technology sesuai dan layak menjadi bahan ajar Geografi, utamanya pada sub materi Mobilitas Penduduk dan Tenaga Kerja. 


\section{DAFTAR PUSTAKA}

Almelhi, Abdullah M. "Effectiveness of the ADDIE Model within an E-Learning Environment in Developing Creative Writing in EFL Students." English Language Teaching 14, no. 2 (2021). https://doi.org/10.5539/elt.v14n2p20.

Andi, Prastowo. Panduan Kreatif Membuat Bahan Ajar Inovatif: Menciptakan Metode Pembelajaran Yang Menarik Dan Menyenangkan. Diva Press, 2011.

Blagg, Kristin, Erica Blom, Megan Gallagher, and Macy Rainer. "Mapping Student Needs during COVID-19 An Assessment of Remote Learning Environments." EDUCATION DATA AND POLICY CENTER, 2020.

Cook, V., P. Warwick, M. Vrikki, L. Major, and R. Wegerif. "Developing Material-Dialogic Space in Geography Learning and Teaching: Combining a Dialogic Pedagogy with the Use of a Microblogging Tool." Thinking Skills and Creativity 31 (2019). https://doi.org/10.1016/j.tsc.2018.12.005.

Dewi, Pratisia, Putra. "Implementasi Pemanfaatan Google Classroom , Google Meet, Dan Instagram Dalam Proses Pembelajaran Online Menuju Abad 21." Jurnal Integrasi Dan Harmoni Inovatif Ilmu-Ilmu Sosial 1, no. 5 (2021): 533-41. https://doi.org/10.17977/um063v1i52021p533-541.

Dewi, Kusuma, and Alfyananda Kurnia Putra. "Pengembangan Bahan Ajar Digital Berbasis STEM Dengan Pendekatan Eco-Spatial Behavior Materi Kependudukan Development of STEM-Based Digital Teaching Materials with an Eco- Spatial Behavior Approach for Population Materials." JPIPS : Jurnal Pendidikan Ilmu Pengetahuan Sosial 7, no. 2 (2021): 92-102. https://doi.org/10.15548/jpips.v7i2.11960.

Dia, Fitri, Amana Turohmah, Alfyananda Kurnia Putra, and Yusuf Suharto. "Improving Critical Thinking Ability : Earthcomm Learning For Watershed Conservation Materials" 3, no. 2 (2021): 99-106.

Hanid, Mohd Fadzil Abdul, Mohd Nihra Haruzuan Mohamad Said, and Noraffandy Yahaya. "Learning Strategies Using Augmented Reality Technology in Education: Meta-Analysis." Universal Journal of Educational Research 8, no. 5 A (2020). https://doi.org/10.13189/ujer.2020.081908. 
Haythornthwaite, Caroline. "Learning, Connectivity and Networks." Information and Learning Science, 2019. https://doi.org/10.1108/ILS-062018-0052.

Ifinedo, Eloho, and Marja Kankaanranta. "Understanding the Influence of Context in Technology Integration from Teacher Educators' Perspective." Technology, Pedagogy and Education, 2021. https://doi.org/10.1080/1475 939X.2020.1867231.

Lin, Lin, Rustam Shadiev, Wu Yuin Hwang, and Shusheng Shen. "From Knowledge and Skills to Digital Works: An Application of Design Thinking in the Information Technology Course." Thinking Skills and Creativity 36 (2020). https://doi.org/10.1016/j.tsc.2020.100646.

Mubarok, H., N. Suprapto, and A. S. Adam. "Using Inquiry-Based Laboratory to Improve Students' Higher Order Thinking Skills (HOTs)." In Journal of Physics: Conference Series, Vol. 1171, 2019. https://doi.org/10.1088/17426596/1171/1/012040.

Nguyen, Thi Phuoc Lai, Thi Huy Nguyen, and Thanh Khiet Tran. "STEM Education in Secondary Schools: Teachers' Perspective towards Sustainable Development." Sustainability (Switzerland) 12, no. 21 (2020). https://doi. org/10.3390/su12218865.

Nieto-Márquez, Natalia Lara, Alejandro Baldominos, and Miguel Ángel Pérez-Nieto. "Digital Teaching Materials and Their Relationship with the Metacognitive Skills of Students in Primary Education." Education Sciences 10, no. 4 (2020). https://doi.org/10.3390/educsci10040113.

Putra, Alfyananda Kurnia. "The Effect of Blended Project-Based Learning with Stem Approach to Spatial Thinking Ability and Geographic Skill” 14, no. 3 (2021): 685-704.

Putra, Alfyananda Kurnia, Sumarmi Sumarmi, Alfi Sahrina, Azni Fajrilia, Muhammad Naufal Islam, and Batchuluun Yembuu. "Effect of MobileAugmented Reality (MAR) in Digital Encyclopedia on The Complex Problem Solving and Attitudes of Undergraduate Student." International Journal of Emerging Technologies in Learning (IJET) 16, no. 07 (2021). https://doi.org/10.3991/ijet.v16i07.21223.

Retnowati, Sri. "The STEM Approach: The Development of Rectangular Module to Improve Critical Thinking Skill." International Online Journal of Education and Teaching 7, no. 1 (2020). 
Salamah, Alim, Rabiatul Adawiah Ahmad Rashid, and Mukhtar. "The Development Of Citizenship Education Learning Models Through The Addie Model To Improve Student Characters At Mulawarman University." Palarch's Journal of Archaeology of Egypt/Egyptology 17, no. 9 (2020).

Steffensen, Lisa. "Climate Change and Students' Critical Competencies: A Norwegian Study," 2020. https://doi.org/10.1007/978-3-030-52229-2_15.

Sumardi, Lalu, Arif Rohman, and Dwi Wahyudiati. "Does the Teaching and Learning Process in Primary Schools Correspond to the Characteristics of the 21st Century Learning?" International Journal of Instruction 13, no. 3 (2020). https://doi.org/10.29333/iji.2020.13325a.

Surma, Tim, and Paul A. Kirschner. "Virtual Special Issue Computers in Human Behavior Technology Enhanced Distance Learning Should Not Forget How Learning Happens." Computers in Human Behavior, 2020. https://doi.org/10.1016/j.chb.2020.106390.

Tubagus, Munir, Suyitno Muslim, and Suriani. "Development of Learning Management System-Based Blended Learning Model Using Claroline in Higher Education." International Journal of Interactive Mobile Technologies 14, no. 6 (2020). https://doi.org/10.3991/IJIM.V14I06.13399. 